\title{
PARTICIPATION IN CURBSIDE RECYCLING SCHEMES AND ITS VARIATION WITH MATERIAL TYPES
}

\author{
R. Woodard, M. K. Harder ${ }^{*} \&$ M. Bench
}

Waste \& Energy Research Group (WERG), School of the Environment, University of Brighton, Lewes Road, Brighton, BN2 4GJ, UK.

This is a post-print version of a paper which was published in Waste Management 26

(8):914-919 (2006) DOI doi:10.1016/j.wasman.2005.08.009

\begin{abstract}
This work is licensed under a Creative Commons Attribution-NonCommercialNoDerivatives 4.0 International License.
\end{abstract}

\footnotetext{
* Corresponding author

Tel: + 44-1273-642539

Fax + 44-1273-642285

E-mail address: m.k.harder@brighton.ac.uk (M.K. Harder)
} 


\begin{abstract}
Local authorities throughout the UK are refining or implementing curbside recycling schemes as they attempt to achieve challenging statutory recycling targets. Despite the importance of curbside schemes there are few published studies that have reported on actual measured levels and frequency of participation by residents, hindering transferability of lessons learned nationally and internationally. This paper reports measurements and analysis over at least four weeks for three different curbside recycling schemes operating in England, with at least 1400 samples in each. It is found that the participation rate is higher in schemes which collect more types of materials. Participation rates of $38 \%, 49 \%$ and $65 \%$ were measured for schemes which collected 1, 2 and 3 material types respectively. The increase appears to be related not only to extra participants setting out the additional materials, but also increased participation for the common materials. It is found that for one scheme, more households tend to set outplastics and cans compared to newspapers.
\end{abstract}

Keywords: Curbside recycling schemes, Participation rates, Recycling targets, Household waste, Participation frequency 


\subsection{Background}

Despite legislative attempts to increase the levels of recycling in the UK, by 2000 only $9 \%$ of household waste was collected for recycling or composting (DETR, 2000). Therefore in 2000 the government set a $25 \%$ recycling target by 2005 as well as subsequent recycling and recovery targets. To meet these targets authorities will have to significantly improve their curbside schemes, and this paper aims to provide information to assist them and others in countries with similar populations and schemes.

Curbside schemes are those where recyclable materials are collected directly from the household for recycling. Few studies have presented extensive and reliable measured information on the levels of participation by residents and the frequency at which they set materials out for collection. This paper presents the results from quantitatively monitoring three curbside recycling schemes operating in similar areas of Sussex, England, using a large sample of households. This provides precise data for other authorities to compare their participation rates against. In addition to knowing how many people participate in a recycling scheme it is very helpful to know how they participate (Thomas, 2001). Therefore in addition to participation rates, a detailed analysis is presented on householder's levels of participation activity within the four weeks of monitoring and the levels of recycling for different materials.

There are many aspectss of a recycling scheme that have a bearing upon its performance. The frequency of collection, provision of a container, approach towards education, incentives, and the demographics of the population are some of the factors 
that can have an influence upon how a scheme operates. These parameters need to be carefully considered so that authorities can plan the best system for their community. Numerous studies have investigated the reasons why residents participate in recycling schemes (e.g. Perrin and Barton, 2001). However, the emphasis of this paper is not to explore these reasons but to report on the actual levels of participation by residents and the frequency at which they place material out for collection. There are very few published studies on this topic and most of them report estimated participation, not actually measured values, often using the indicator called the participation rate.

\subsection{Participation rate measurements}

The participation rate is used to record levels of participation in a recycling scheme. In the UK the participation rate is defined "as the number of households that actively take part in recycling over a four week period" (DETR, 1999). Some residents may not place recyclable materials out in each collection (e.g. weekly or fortnightly) as they may not generate enough material or they may forget. However, if the household actively recycles it is likely they will place materials out at least once in a four-week period, and this is the period that authorities are now required to report for. Some studies suggest that 4 weeks is too short a surveying period and 8 weeks may be more appropriate to give a true reflection in the levels of participation (Tucker et al., 2000).

Participation Rate: $\quad$ Number of households placing materials out $\quad x 100 \%$ for collected at least once in a four week period Total number of households 
The preferred form of recording the participation rate is by collecting quantitative data by directly surveying how many households set recyclable materials out for collection. However, many local authorities use questionnaires, postal or face-to-face, while other authorities use 'focus groups' to estimate participation, even though extensive studies show that the claims of residents do not always reflect their actions (e.g., Tucker and Speirs, 2003b; Woolam et al., 2003). A recent publication that reviewed the results from previous waste awareness studies shows that $72 \%$ to $82 \%$ of those questioned claim to recycle at least once a month (Resources Recovery Forum, 2002) which is not reflected in the tonnage of material collected.

It should be noted that a high participation rate does not necessarily correspond to a high recycling rate (Wang et al., 1997) as the measurement of participation does not take into account the quantity of material placed out by an individual for recycling. The weighing of each individual recycling box is very labour-intensive, and is not a viable method for measuring the recycling rate. Rather, the comparison of the total weight of recyclates collected compared to residual waste for a given population is easier and usually sufficient.

\subsection{Review of published participation rates for the UK}

A review of some reported participation rates from published studies from the UK and Ireland is presented in Table 1. Although the figures are presented in those studies as 'measured', it is not usually clear whether they were actually indirectly obtained via questionnaires or focus-groups. In some instances the sample sizes were small i.e. less than 300 . Quoted rates vary from $92 \%$ for a multi-material collection to $28 \%$ for a newspaper recycling scheme (Perrin and Barton 2001; Tucker et al 1997). 
Many studies have also been conducted into the levels of participation in North America. Folz (1999) reported that the mean participation rate throughout the USA in 1996 was $73 \%$. Everett and Peirce (1993) found that approximately 50\% of recycling schemes operating schemes in the USA were mandatory. Feiock and West (1996) suggest that participation is higher in cities where mandatory curbside schemes operate and Oskamp et al., (1996) found that participation is higher in commingled collection schemes than segregated collections.

\section{Insert Table 1}

\subsection{Frequency of Levels of participation}

Though the participation rate is a useful tool it does not take into account the level or frequency at which residents recycle. Several studies have been carried out where residents have been questioned in regards to how regularly they recycle. CorralVerdugo (1997) used a four point scale varying from 'always' to 'never' recycling, Knussen et al., (2004) used a seven point scale from 'no intention' to 'firm intention'. However, as with estimated participation rates there are uncertainties with these results as they are claimed behaviour rather than actual behaviour. In regards to actually measuring recycling frequency there are few data sets published. Oskamp et al., (1996) surveyed two different schemes and found that 13\%-22\% of households placed materials out every week for collection during an 8 week period.

\section{Methodology}


In this work, data were collected over four weeks for each of three curbside recycling schemes during January to May of 2002. Surveying was conducted on a house-byhouse basis, allowing not only the participation rate to be directly measured but also for the classification of each household as a high-, medium-, low- and non-recycler. This earmarking of houses in terms of their measured commitment to recycle is a useful tool allowing detailed analysis, and is not commonly used; the idea is not usually brought up, and when it is, it is considered labour-intensive.

One aim of this work was to investigate the hypothesis that levels of participation in recycling schemes are greater for those with the inclusion of more materials. The three schemes selected for analysis were therefore chosen for the varying range of materials that they collected. A data 'snap-shot' of each scheme was collected for comparison; this study did not involve the changing of the parameters of any one scheme.

Scheme A collected only newspapers \& magazines, collected on a fortnightly basis. Scheme B collected newspapers \& magazines and also mixed paper in the same collection, fortnightly. Scheme C collected newspapers \& magazines on alternate weeks with cans and plastic drinks bottles (mostly HDPE and PET). Table 2 provides a summary of the main parameters of each of the three schemes. For brevity, the category of newspapers \& magazines will be labelled 'newspapers' for the rest of this paper.

Each of the three studies were undertaken in areas of similar demographics with the surveying conducted at some time between the end of January to the beginning of 
May (see details in Table 2), avoiding holiday periods. No promotional activities took place in any areas in the preceding three months, and the service quality was similar in all three schemes. Several different collection sub-rounds were used in each scheme. All three of the schemes covered similar areas of population density averaging 20-40 people per hectacre (Office of National Statistics 2004). All of the sets were taken in similar parts of the UK, where unemployment rates are generally similar at around 3\%, waste production is typically 330-470 $\mathrm{kg}$ per capita per annum, and the residents live in towns rather than villages.

The demographics for the three schemes are also similar, using ACORN (A Classification Of Residential Neighbourhoods) profiles (CACI, 2002). These are designed for marketing purposes, rather than detailed demographic studies, and care must be taken not to use them as anything other than a general guide rather than a reliable indicator of demographics. However, broadly speaking, ACORN profile A designates typically higher income, higher educated households, through to profile $\mathrm{F}$ which typically denotes lower income and household education. These profiles are a well-known tool for approximate information on demographics, and are widely available. All three schemes had similar mixes of ACORN groups D, E and F, except that Scheme B also had some ACORN groups A,B and C present. The overall data was checked for any correlation between ACORN groups and measured participation rates in this study, and none was found. Neither was any found when each Scheme was considered individually. A detailed presentation of this data is given in Harder et $a l, 2005$. 
3 Results

\section{Insert Table 2}

\subsection{Participation rates and levels of participation}

From Table 2 it can be seen that the participation rates varied from $38 \%$ in Scheme A to $65 \%$ in Scheme C.

In Schemes A and B the recyclable materials were collected fortnightly, and households were classified as non-, medium- or high-recyclers if they set out materials 0,1 or 2 times respectively in the four week surveying period. In Scheme C the residents had an opportunity to set out materials each week, and they were categorised as non-, low-, medium- and high- recyclers if they set out materials $0,1,2$ and 3-4 times respectively during the surveying period. Table 3 summarises the observed breakdown of the schemes' households into these groups, allowing a comparison. In the case of Scheme $\mathrm{C}$ a further breakdown is provided for the subgroups.

\section{Insert Table 3}

\subsection{Differences in participation frequencies between Schemes}

Table 3 is useful to show which type of recyclers contributed to the overall increases in participation rates. In Scheme B, participation rates were $49 \%$, compared to $38 \%$ in Scheme A. Of this eleven-point difference, only four are due to extra medium recyclers, whereas seven points are due to extra high recyclers. One possible interpretation is that mixed paper is easier to recycle and thus more participants can 
do it regularly; another is that high recyclers prefer to set out mixed papers rather than newspapers.

A different contribution of medium and high recyclers is found, however, when comparing results from Schemes $\mathrm{A}$ and $\mathrm{C}$ - participation rates of $38 \%$ and $65 \%$ respectively. Of the 27 point difference in participation rates, seventeen are from extra contributions from low recyclers participating-households that would otherwise be non-participants. This indicates a possible link between the addition of cans and plastics to a curbside scheme to a decrease in the number of non-recyclers. Another possible interpretation is that recyclers generally prefer to set out cans and plastics to newspapers, and this could explain why Scheme $\mathrm{C}$ had a higher participation rate.

\subsection{Increased participation and additional materials}

The results from Scheme $\mathrm{C}$ can be used to investigate the interpretation that greater participation occurs when more materials are collected only because of the new materials collected. Such analysis is only possible for Scheme C, as only this scheme has different materials collected on alternate weeks - and even so, Scheme C only allows for a comparison of newspapers against cans and plastics. Table 4 shows the results for Scheme $\mathrm{C}$ showing the participation by material and number of set-outs.

\section{Insert Table 4.}

Table 4 shows several interesting points. Of the $65 \%$ households participating in Scheme C, 46.9\% set out newspapers once in the two fortnightly collections 
measured. In comparison, Scheme A, which only collects newspapers, had a 38\% participation rate; therefore Scheme $\mathrm{C}$ has an additional $8.9 \%$ of residents setting out newspapers for collection. Scheme $\mathrm{C}$ also has a further $18.4 \%$ who participate by setting out only cans and plastics. Thus the provision of a collection scheme which accepts two further materials has a larger number setting out the same material (newspapers) as well as further participants apparently only interested in setting out the additional materials (cans and plastics) compared to Scheme A.

Although newspapers weigh more and thus contribute more by weight, the data shows considerably more recyclers in Scheme $\mathrm{C}$ set out cans and plastics. This effect seems to exist for those who recycled once in four weeks (10.6\% to $6.1 \%)$, twice in four weeks $(7.8 \%$ to $2.5 \%)$, and three times in four weeks $(12.5 \%$ to $5.8 \%)$. The results conflict with the findings from Perrin and Barton (2001) that showed paper was more commonly set out than cans. In this study, the inclusion of plastics appears to be significant, and is a point worthy of further investigation.

\section{Discussion}

Scheme $\mathrm{C}$ had the highest participation rate at $65 \%$ whilst $\mathrm{A}$ had the lowest at $38 \%$.

There are many different parameters that influence the propensity of an individual to recycle. In this instance a reason for the variation in the levels of participation recorded could be the range of materials collected. Scheme A collected only newspapers \& magazines and reported the lowest participation rate of $38 \%$. Scheme B incorporated newspapers \& magazines with mixed paper and achieved a participation rate of $49 \%$, and scheme $\mathrm{C}$ included newspapers and magazines with aluminium and 
steel cans plus PET and HDPE plastic bottles and reported the highest participation rate of $65 \%$. Figure 1 shows the results from Table 1 along with the new results provided by this study. For all the schemes collecting one material only, newspapers, the highest participation rate is $51 \%$, whilst schemes collecting a range of materials generally report higher levels of participation.

\section{Insert Fig. 1}

There are several possible explanations for this trend. The first is the quantity of materials that are available in the waste stream for capture. Before each curbside scheme was implemented, data was collected on the composition of the residual waste from the three areas monitored. Whereas scheme A only catered for $15 \%$ of the mass of materials present in the residual waste stream, scheme B catered for $23 \%$, and scheme C for $26 \%$.. By volume, Scheme C would be even more useful to the householder as the scheme collected cans and plastics which are bulky and which householders thus seem interested in diverting from their waste. Higher participation and capture of materials in this Scheme might be explainable because of this.

This possible effect is an interesting one which merits further investigation. If it is true that participation of householders is influenced by the bulk of recyclates collected, then this could be easily incorporated in planning for new or revised schemes. It would also be interesting to determine the root source of the preference e.g. whether the householders are driven more by increased satisfaction at having less waste for disposal or at having more recyclates to 'contribute'. 
A further reason that the participation rate is higher when more material types are collected may arise from the fact that all households do not generate the same quantity of each material type. For example, certain households will not have much newspaper waste, while others might not have many empty cans. Tucker (1999) has shown that some householders believe that curbside recycling schemes are of little use to low users of newspaper. By providing a collection service of more materials, one would expect that a greater percentage of the households would see participation in recycling as an option, simply because there is a greater chance that the material(s) they prefer to recycle are collected.. For example, in Scheme C, $8 \%$ of households set out newspapers and magazines only, and $18 \%$ only set out cans and plastics only (see Table 4). If the scheme omitted either material categories, they may lose those participants.

It is worthwhile to note that the three schemes studied here were instigated by the local authorities. Scheme $\mathrm{C}$ was not more comprehensive in reaction to demand by the population, but was simply presented to them as a standard scheme. Otherwise, it might be possible that the population in, for example, Scheme C, might be selfselective as strong supporters of recycling, and thus not comparable to the other two schemes.

A further contribution to the trend shown in this study may be the perception of the collection service. Residents are used to having their waste collected each week and the integration of a curbside recycling service is a relatively recent addition. When only one material is included in the curbside scheme, the emphasis of the whole collection system is still on waste collection. When more materials are incorporated 
into the collection of recyclables, the population may shift their perception of the process from one of waste collection with a limited recycling service to a system dominated by recycling with minimal actual 'residual waste'. Schemes which facilitate this evolution should benefit from a stepwise increase in both participation rates and in the amounts of recyclable material collected from each household. Some authorities are moving towards this kind of recycling dominated system by also reducing the frequency of collection of residual waste to fortnightly whilst also increasing the frequency and range of recyclable materials collected. For further information on alternate weekly collection schemes see Woodard et al., (2001), Jones and Read (2001).

It should be noted that though some households may have been observed as never participating in the curbside scheme they may have been recycling through other mechanisms (transfer stations, drop-off centres, etc). Research by McDonald and Oates (2003) has shown that $62 \%$ of those residents not participating in a curbside scheme recycled through other means. Further research by Tucker and Speirs (2003a) suggests that residents provided with a curbside service may recycle a lesser range of materials than those that have to use drop-off centres to recycle. Whilst a greater percentage of householders may recycle when a curbside scheme is in place, their recycling activity may be somewhat constrained to just what the scheme collects.

\section{Conclusions}

This paper provides considerable detail on samples of over 1400 households on each of three different curbside schemes. The data indicates that higher participation rates are linked to a larger number of materials collected. A bias for participants to set out 
cans and plastics over newspapers is shown overall as well as separately for low-, medium- and high-recyclers. The schemes that collect more materials show more participation with the materials common to other schemes as well as the additional material catered for.

In this work, information from three existing schemes was used to investigate the variation of participation with the number of materials collected. Although this was an efficient use of detailed primary data collected by the same research group, using the same methodology, nonetheless it involved three different schemes and was not designed specifically to test the ideas presented here. For example, the schemes were investigated at slightly different times of year, may have subtle demographic differences, and did not have control groups. Although no promotion activities took place immediately before the data collection, the schemes may have been presented very differently to the householders through different promotional methods. Additionally, Scheme C uses alternate week collections whereas the others use weekly collections, which might be responsible for some differences in participation. Ideally, the result indicated would best be directly tested using one single group with varying number of materials, and a control group.

However, it remains that a significant effect is shown through the use of the data presented, whereby the schemes that collect more materials show more participation with all material groups.

This level of detail has only been possible to report due to the collection of the data on a house-by-house basis, allowing participants to be tracked over a period of time. It 
is suggested that this method be used where possible by those wishing to understand the recycling tendencies of their populations in detail. 


\section{References}

CACI. 2002. ACORN the complete consumer classification. CACI, London, UK.

Coggins, C., 1994. Who is the recycler? Journal of Waste Management \& Resource Recovery, 1, 69 - 75 .

Corral-Verdugo, V., 1997. Dual 'realities' of conservation behaviour: self reports vs observations of re-use and recycling behaviour. Journal of Environmental Psychology, 17, 135 - 145.

DeBurca, D., and Dodd, V. A., 1996. Curbside Recycling Schemes as a Municipal Solid Waste Management Option. Air \& Waste Management Association, $89^{\text {th }}$ Meeting \& Exhibition, Nashville, Tennessee.

DETR, 1999. Monitoring and evaluating recycling, composting and recovery programmes. HMSO, London, UK.

DETR, 2000. Waste Strategy 2000. HMSO, London, UK.

Everett, J. W. and Peirce. J. J., 1993. Curbside recycling in the USA: convenience and mandatory recycling. Waste Management \& Research, 11, 49 - 61.

Feiock, R. C. and West, J., 1996. Explaining Success of Local Recycling Programs: A Reassessment. International Journal of Public Administration. 19, 7: 1065 - 1087. 
Folz, D. H., 1999. Municipal Recycling Performance: A Public Sector Environmental Success Story. Public Administration Review, 59, 336 - 345.

FOE, Friends of the Earth, 2001. Recycling in action. London, UK.

Harder, M. K., Woodard, R. and Bench, M. L., 2005. Two Measured Parameters Correlated to Participation Rates in Curbside Recycling Schemes in the UK, Environmental Management (in print).

Jones, S. R. and Read, A. D., 2001. Green Fingered - Green Minded: Waste Management and the Organic Waste Stream. Proceedings of Towards the Future Waste in the 21st Century, $30-40$.

Knussen, C., Yule, F., MacKenzie, J. and Wells, M., 2004. An analysis of intentions to recycle household waste: The roles of past behaviour, perceived habit, and lack of facilities. Journal of Environmental Psychology, 24, 237 - 246.

Lyas, J., Shaw, P. and Van-Vugt, M., 2002. Survival bag behaviour in a London Borough: Householder behaviour, motivations and barriers. IWM Proceeding 2002, Torbay, UK.

McDonald, S. and Oates, C., 2003. Reasons for non-participation in a kerbside recycling scheme. Resources, Conservation and Recycling, 39, 369 - 385 
Moloney, D., 2002. Research into householder participation in recycling schemes. Warmer Bulletin, July 2002, 16 - 19.

Office of National Statistics. 2004. Census 2001. www.statistics.gov.uk/census2001/

Oskamp, S., Zelezny. L., Schultz, P. W., Hurin, S. and Burkhardt, R., 1996. Commingled versus separated curbside recycling - does sorting matter? Environment and Behaviour, 28, 1, 73 - 91.

Perrin, D. and Barton, J., 2001. Issues associated with transforming household attitudes and opinions into materials recycling: a review of two recycling schemes. Resources, Conservation and Recycling, 33, $61-74$.

Resource Recovery Forum, 2002. Household waste behaviour in London. RRF, Skipton, UK.

Thomas, C., 2001. Public understanding and its effect on recycling performance in Hampshire and Milton Keynes. Resources, Conservation and Recycling, 32, 259 -

Tucker, P., Murney, G., and Lamont, J., 1997. Participation in Recycling: A Comparative Study of Four Kerbside Recycling Schemes. Journal of Waste Management \& Resource Recovery, 4, 11 - 23.

Tucker, P., 1999. A survey of attitudes and barriers to kerbside recycling. Environmental and Waste Management, 2, 1, 55 - 63. 
Tucker, P., Grayson, J. and Speirs, D., 2000. Integrated effects of a reduction in collection frequency for a kerbside newspaper recycling scheme. Resources, Conservation and Recycling, 31, 149 - 170.

Tucker, P. and Speirs, D., 2003a. Relationships amongst waste management behaviours. CIWM Scientific \& Technical Review, 4, 1, 2 - 8.

Tucker, P. and Speirs, D., 2003b. Count me as doing my bit: an appraisal of the accuracy of waste attitude/behaviour surveys. CIWM Scientific \& Technical Review, $4,2,9-18$.

Wang, F. S., Richardson, A. J. and Roddick, F. A., 1997. Relationships between setout rate, participation rate and set-out quantity in recycling programs. Resources, Conservation and Recycling, 20, 1 - 17.

Woodard, R., Bench, M., Harder, M. K. and Philip. M., 2001. Evaluating the performance of a fortnightly collection of household waste separated into compostables, recyclates and refuse in the south of England. Resources, Conservation and Recycling, 31, $265-284$.

Woolam, T.C., Emery, A., Griffiths, A. J. and Williams, K.P., 2003. A comparison of intended and claimed recycling behaviour to actual in a new kerbside scheme. CIWM Scientific \& Technical Review, 4, 3, 2 - 9. 
Table 1

Reported measured participation rates in the UK

\begin{tabular}{|c|c|c|c|c|}
\hline $\begin{array}{l}\text { Area } \\
\text { (all in UK \& Ireland) }\end{array}$ & $\begin{array}{l}\text { Participation } \\
\text { rate }\end{array}$ & Detail & $\begin{array}{l}\text { Number of } \\
\text { Materials } \\
\text { collected }\end{array}$ & Date \\
\hline $\begin{array}{l}\text { Bradford } \\
\text { (Perrin and Barton, 2001) }\end{array}$ & $92 \%$ & $\begin{array}{l}\text { Mixed multi } \\
\text { material collection }\end{array}$ & 6 & 1999 \\
\hline $\begin{array}{l}\text { Unknown } \\
\text { (Moloney, 2002) }\end{array}$ & $90 \%$ & $\begin{array}{l}\text { Alternate collection } \\
\text { of garden waste and } \\
\text { refuse and dry } \\
\text { recyclables }\end{array}$ & Unknown & 2002 \\
\hline $\begin{array}{l}\text { Dublin (DeBurca and Dodd, } \\
\text { 1996) }\end{array}$ & $75 \%$ & $\begin{array}{l}\text { Dry recyclable } \\
\text { collection }\end{array}$ & 4 & 1993 \\
\hline $\begin{array}{l}\text { Bath \& NE Somerset } \\
\text { (FoE, 2001) }\end{array}$ & $76 \%$ & $\begin{array}{l}\text { Co-mingled dry } \\
\text { recyclables } \\
\text { collected weekly in } \\
\text { boxes }\end{array}$ & 4 & 1999 \\
\hline $\begin{array}{l}\text { Havering, London } \\
\text { (Lyas at al., 2002) }\end{array}$ & $71 \%$ & Survival bags & Unknown & 2000 \\
\hline $\begin{array}{l}\text { Luton } \\
\text { (Coggins, 1994) }\end{array}$ & $63 \%$ & Dry recyclables & Unknown & 1994 \\
\hline $\begin{array}{l}\text { Milton Keynes } \\
\text { (Coggins, 1994) }\end{array}$ & $58 \%$ & $\begin{array}{l}\text { Co-mingled } \\
\text { recyclables. } \\
\text { scheme data }\end{array}$ & Unknown & 1991 \\
\hline $\begin{array}{l}\text { Bristol } \\
\text { (FoE, 2001) }\end{array}$ & $52 \%$ & $\begin{array}{l}\text { Co-mingled dry } \\
\text { recyclables } \\
\text { collected weekly in } \\
\text { boxes }\end{array}$ & 4 & 2001 \\
\hline $\begin{array}{l}\text { Flyde } \\
\text { (Tucker } \text { et al., 1997) }\end{array}$ & $51 \%$ & $\begin{array}{l}\text { Newspaper } \\
\text { collection only }\end{array}$ & 1 & 1997 \\
\hline $\begin{array}{l}\text { Sheffield } \\
\text { (Coggins, 1994) }\end{array}$ & $40 \%$ & Pilot & Unknown & 1993 \\
\hline $\begin{array}{l}\text { Wyre } \\
\text { (Tucker } \text { et al., 1997) }\end{array}$ & $35 \%$ & $\begin{array}{l}\text { Newspaper } \\
\text { collection only }\end{array}$ & 1 & $\begin{array}{l}1996- \\
1997\end{array}$ \\
\hline $\begin{array}{l}\text { Glasgow } \\
\text { (Tucker } \text { et al., 1997) }\end{array}$ & $33 \%$ & $\begin{array}{l}\text { Newspaper } \\
\text { collection only }\end{array}$ & 1 & 1997 \\
\hline $\begin{array}{l}\text { East Dunbartonshire/N. } \\
\text { Lanark (Tucker et al., 1997) }\end{array}$ & $28 \%$ & $\begin{array}{l}\text { Newspaper } \\
\text { collection only }\end{array}$ & 1 & 1997 \\
\hline
\end{tabular}


Table 2

Summary of scheme characteristics of Schemes A, B, C carried out in this study

\begin{tabular}{|c|c|c|c|}
\hline Scheme & $\mathrm{A}$ & $\mathrm{B}$ & $\mathrm{C}$ \\
\hline Year of survey & 2002 & 2001 & 2002 \\
\hline $\begin{array}{l}\text { Average house size } \\
\text { (people per household) }\end{array}$ & 2.09 & 2.45 & 2.38 \\
\hline Population aged $18-74$ & $75 \%$ & $72 \%$ & $71 \%$ \\
\hline Employed (Age 18-74) & $60 \%$ & $69 \%$ & $68 \%$ \\
\hline $\begin{array}{l}\text { Educated above high } \\
\text { school level (Age 18- } \\
74 \text { ) }\end{array}$ & $29 \%$ & $15 \%$ & $23 \%$ \\
\hline $\begin{array}{l}\text { Kg of household waste } \\
\text { collected per head }\end{array}$ & 468.9 & 333.9 & 363.0 \\
\hline Period of of survey & January-February & March-April & April-May \\
\hline $\begin{array}{l}\text { Number of } \\
\text { Materials collected }\end{array}$ & 1 & 2 & 3 \\
\hline $\begin{array}{l}\text { Types collected } \\
\text { (Brackets indicate those } \\
\text { collected together in } \\
\text { one container) }\end{array}$ & $\begin{array}{l}\text { (newspapers\& } \\
\text { magazines) }\end{array}$ & $\begin{array}{l}\text { (newspapers } \& \\
\text { magazines }+ \\
\text { mixed paper) }\end{array}$ & $\begin{array}{l}\text { (newspapers \& } \\
\text { magazines) } \\
\text { (cans }+ \text { plastic } \\
\text { bottles) }\end{array}$ \\
\hline $\begin{array}{l}\text { Overall District } \\
\text { Recycling Rate } \\
\text { (at time of analysis) }\end{array}$ & $10 \%$ & $13 \%$ & $13 \%$ \\
\hline $\begin{array}{l}\text { Collection Frequency } \\
\text { (recyclables) }\end{array}$ & Fortnightly & Fortnightly & Alternate weeks ${ }^{2}$ \\
\hline Container types & $\begin{array}{l}\text { Box } \\
\text { Baskets } \\
\text { Bags }\end{array}$ & $\begin{array}{l}\text { Reusable } \\
\text { Bag }\end{array}$ & Baskets \\
\hline $\begin{array}{l}\text { Collection Frequency } \\
\text { (residual waste) }\end{array}$ & Weekly & Weekly & Weekly \\
\hline $\begin{array}{l}\text { Number of households } \\
\text { monitored }\end{array}$ & 1473 & 2047 & 1921 \\
\hline $\begin{array}{l}\text { Participation rate } \\
\text { (Overall) }\end{array}$ & $38 \%$ & $49 \%$ & $65 \%$ \\
\hline $\begin{array}{l}\text { Highest participation } \\
\text { rate on road }\end{array}$ & $67 \%$ & $80 \%$ & $100 \%$ \\
\hline $\begin{array}{l}\text { Lowest participation on } \\
\text { road }\end{array}$ & $15 \%$ & $1 \%$ & $0 \%$ \\
\hline
\end{tabular}

${ }^{1}$ The Recycling Rate is the ratio of household waste recycled to that not recycled.

${ }^{2}$ Alternate weeks collections have one set of materials collected one week, alternating with a different set collected the second week, repeated.

${ }^{3}$ Participation rates give the percentage of households who have set out recyclates for collection at least once in four consecutive weeks. 
Table 3

Breakdown of participation frequency in Schemes A, B and C

\begin{tabular}{|c|c|c|c|c|c|c|}
\hline & \multicolumn{2}{|c|}{ Scheme A } & \multicolumn{3}{|c|}{ Scheme B } & Scheme C \\
\hline $\begin{array}{l}\text { Recycler } \\
\text { Participation }\end{array}$ & $\begin{array}{l}\text { No. of } \\
\text { set outs }\end{array}$ & $\begin{array}{l}\% \text { houses } \\
\text { recorded }\end{array}$ & $\begin{array}{l}\text { No. of } \\
\text { set outs }\end{array}$ & $\begin{array}{l}\% \text { houses } \\
\text { recorded }\end{array}$ & $\begin{array}{l}\text { No. of } \\
\text { set outs }\end{array}$ & $\begin{array}{l}\% \text { houses } \\
\text { recorded }\end{array}$ \\
\hline Non & 0 & 62 & 0 & 51 & 0 & 35 \\
\hline Low & - & - & - & - & 1 & 17 \\
\hline Medium & 1 & 17 & 1 & 21 & 2 & 19 \\
\hline High & 2 & 21 & 2 & 28 & 3 or 4 & $29(18+11)$ \\
\hline $\begin{array}{l}\text { Total } \\
\text { participation }\end{array}$ & & 38 & & 49 & & 65 \\
\hline
\end{tabular}


Table 4

Detailed breakdown of participation rates $(\%)$ in Scheme $\mathrm{C}$ by number of set-outs and material set-out over the four week monitoring period.

\begin{tabular}{|c|c|c|c|c|}
\hline \multirow{2}{*}{$\begin{array}{l}\text { Number of } \\
\text { Set-outs: }\end{array}$} & \multicolumn{3}{|c|}{ Cans \& Plastics } & \multirow[b]{2}{*}{ Total $\%$} \\
\hline & 0 & 1 & 2 & \\
\hline 0 & 34.8 & 10.6 & $\overline{7.8}$ & 53.2 \\
\hline & 6.1 & 8.5 & 12.5 & 27.1 \\
\hline$\underset{\mathbb{\pi}}{\mathbb{\pi}} 2$ & 2.5 & 5.8 & 11.4 & 19.7 \\
\hline 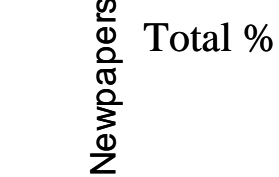 & 43.4 & 24.9 & 31.7 & $100 \%$ \\
\hline
\end{tabular}

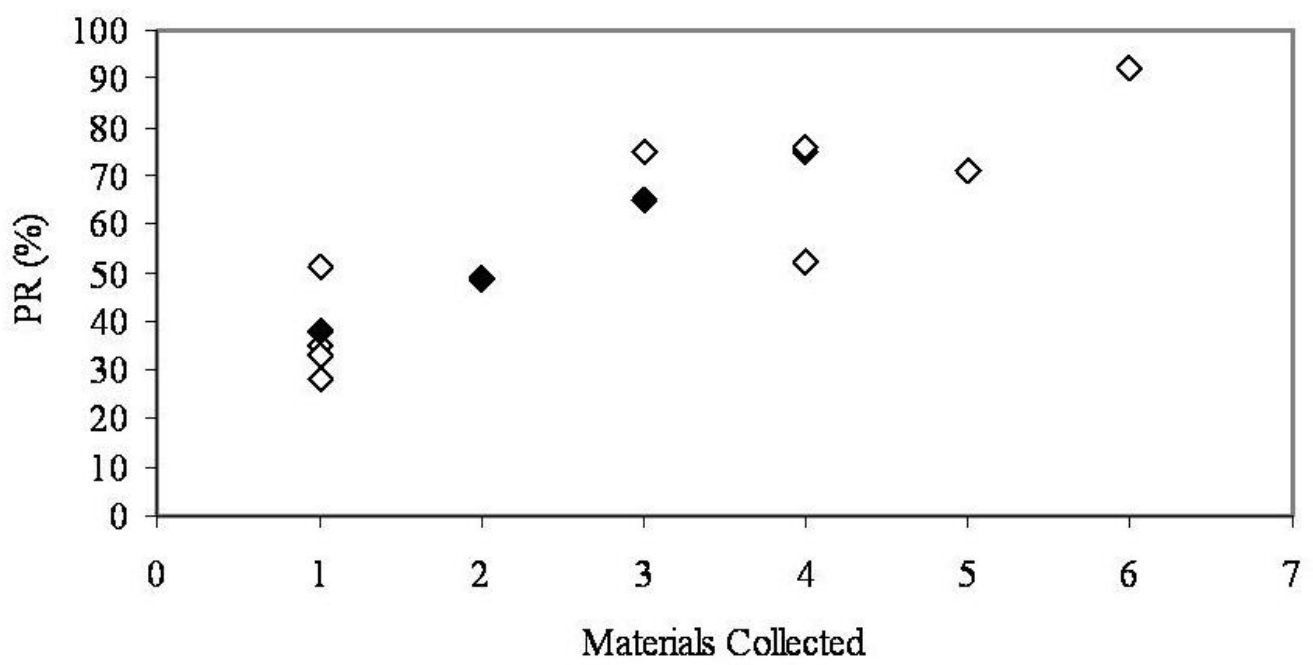

Fig. 1. Relationship between the number of materials collected in a kerbside service and the participation rate, from published studies (listed in Table 1) and the three schemes reported in this study (denoted in black) 